\title{
Interrogating the "Animal": An Investigation into the Ethics of Man-Animal Divide
}

\author{
Swagata Singha Ray \\ Faculty Gurudas College, Kolkata, swagata.swagata@gmail.com
}

\begin{abstract}
Humanity defines itself through an animal other, the animal in Jacques Derrida's definition of "absolute alterity," cannot return the human gaze. In this paper I explore the possibilities of accommodation and hospitality which posthuman philosophy provides in conceptualizing the position of alterity of the "animal". Building on the writing of Jacque Derrida and Giorgio Agamben I will argue how Posthumanism can radicalize the way in which the anthropocentric worldview looks at the animal as other, questioning the positioning and relevance of speciesism and species boundary. Also, the issue of agency has been interrogated in this research article. I have also argued for a new mode of conceptualizing the "other" / the "animal" which abolishes the hierarchical view of anthropocentric conception of nonhuman but instead views the other from the lens of companionship, borrowing from the ideas of "companionship" and "Chuthulucene" of Donna J. Haraway. The paper is an attempt to expand the humanist exclusionary boundaries and is an exercise in developing a posthuman ethics through which the category of human can be radically questioned and can be made more hospitable.
\end{abstract}

\section{Keywords}

Animal, Anthropocene, Chuthulucene, Ethics, Posthuman.

The dominant Western rationalist culture and metaphysics is greatly dependent upon a dualistic approach producing binaries such as mind/body, human/nature or civilized/ primitive. There is a constant privileging of the mind over matter, human over non-human, science and technology over natural systems, and the dualism initiates a constant silencing of the natural and the animal. J. M. Coetzee writes about the silencing of the animal in his extraordinary text Lives of Animals where the fictive author Elizabeth Costello says the following:

In the olden days the voice of man, raised in reason, was confronted by the roar of the lion, the bellow of the bull. Man went to war with the lion and the bull, and after many generations won that war definitively. Today these creatures have no more power. Animals have only their silence left with which to confront us. Generation after generation, heroically, our captives refuse to speak to us. (Coetzee, 2006, p.123)

The silencing of the animal- the other, is a part of the "othering" process which the anthropocentric metaphysics initiates. Jacques Derrida in his various works points out the politics

This Open Access article is published under a Creative Commons Attribution Non-Commercial 4.0 International License (http://creativecommons.org/licenses/by-nc/4.0/), which permits non-commercial re-use, distribution, and reproduction in any medium, provided the original work is properly cited. For citation use the DOI. For commercial re-use, please contact editor@rupkatha.com. 
of anthropocentricism and its desire to substantially stabilize an onto-theological notion of man. For instance, in Of Grammatalogy, Derrida argues that the category of man doesn't possess any essentialist trait, anything "proper" that is to say anything essential in an exclusive or binary sense. The idiom human gains meaning only in relation to a series of excluded terms, identities and categories foremost among them being the nature and the animal. Similarly, in Glas Derrida notes that the ontotheological apparatus of humanism has yet to come to terms with the second blow given by Darwin's violent decentring of the narcissistic image of man as reflection of logocentric God figure, which shattered the religious basis of the man- animal divide. In his The Animal that therefore I Am Derrida focuses on the ontological repression of the animal and finds a correlation between the technological development and the subjugation of the animal. Derrida writes, contrasting the change in the nature of treatment of the animal with the rise of technological advancements:

It is all too evident that in the course of the last two centuries these traditional forms of treatment of the animal have been turned upside down by the joint developments of zoological, ethological, biological, and genetic forms of knowledge, which remain inseparable from techniques of intervention into their object, from the transformation of the actual object, and from the milieu and world of their object, namely, the living animal. (Derrida, 2008, p. 25)

This passage from Derrida elicits an interrogation in search of the factors responsible for the increased subjugation and objectification of the animal in the recent times, which is in tandem with the meteoric rise of technological advancements made by the human race "what besides the development of science and technology, has been the driving force behind this increased subjection of the animal? Economic force? Human chauvinism? Exponential population growth? Widespread ethicopolitical insensitivity?" (Calarco, 2008, p.119).

The echo of the transhumanist school of thought can be traced in the proliferation of the genetic manipulation, artificial insemination and mechanised methodologies in the field of animal husbandry and food industry against which Derrida expresses his reservations. The nexus of anthropocentric world view binds within itself the capitalist desire for profit maximization which it masks under the guise of "the service of a certain being and the putative human well-being of man" (Derrida: 25). The propensity to view the other, the animal, as resources to be exploited for the commodity fetishism of the human beings has been critiqued by various Animal rights critique such as Peter Singer and Tom Regan who object against the unethical treatment of the animal. However, the exploitation of the "bare life" -i.e. the animal without the faculty to sign the contract of moral and civic treatment runs its course unabated. The introduction of the technological aspects into the treatment of the animal has been a very old practice in the history of man- animal interaction. As Nicholas Rose points out in his celebrated work Politics of Life itself: Biomedicine, Power and Subjectivitiy in the Twenty-First Century.

Humans put the vital properties of the natural world in service for themselves from their inception, with the domestication of animals and plants. They turned these properties into technologies, when they harnessed the milk producing capacities of cows, and the silk producing capacities of the silkworm to the generation of bio-value: capturing, 
domesticating disciplining, instrumentalizing, the vital capacities of living creatures. (Rose, 2001, p. 33)

This is precisely the reason why Regan advocates a total dissolution of commercial animal agriculture, not only such system produces scope for animal cruelty in form of their bodily exploitation but it also necessitates constant attempts for genetic modulations and modifications as in the system driven by capital multiplication various research and development programs are initiated to ontologically alter the animal to suite the human requirements. With the developments made in the genetic science and engineering such activities have become common practice. This proliferation of genetic manipulation to alter the constitution of bios- both human and non human organism purely for capitalist profit maximization is termed as biocapitalism by thinkers like Rose and K. Sundar Rajan. As Rose points out "Energized by the search for biovalue, novel links have formed between truth and capitalization, the demands for shareholder value and the human value invested in the hope for cure and optimality. A new economic space has been delineated - the bioeconomy - and a new form of capital - biocapital" (Rose, 2001, p. 6). Kaushik Sunder Rajan holds that the bio-capital is symptomatic of capitalism rather than a rupture from it. According to Rajan "some of the key specificities for biocapitalism stem from the epistemic changes taking place within the life sciences, and this is where genomics becomes a conjuncture of profound consequence" (Rajan, 2006, p. 136). This stems from the propensity to evaluate live in tandem with its value in market, an occurrence which is a result of reconfiguration of meaning of "life itself" as "biocapitalism stems from the involved implosions of the economic with the epistemic, and further with epistemologies concerning "life itself" (Rajan, 2006, p.130). Biocapitalism is defined by its treatment of bare life- as commodity. The shift from the pharmaceutical industry to biotech industry is marked by a radical shift in nature of the parlance and production invoked and involved in two, there is a shift in the industry from drug development to drug discovery, as the industry shifts from production of drugs through organic chemical synthesis to active protein kinetics and dynamics. Rajan points out that the drugs and health industry today is increasingly dependent on transmutation of genetic matter for therapeutic purpose as "discovery work is not about the production of an object or commodity as much as it is about, on the one hand, the identification of possible lead molecules that might successfully be converted to therapeutic molecules" (Rajan: 130). Neo-liberalism and the transhuman philosophy which has come to dictate the therapeutic sector, treats the living genetic material as commodity to be patented, developed and marketed. Humanist dualism, the distinction between the self as human and animal as other, which had initiated the anthropocentric valorization of the human, ironically embarks on a journey where even human life becomes a commoditized object to be marketed for the economic benefit of some humans. Human genetic engineering and increased use of technological proliferation has given rise to drastically anti-material, anti-corporeal and significantly, even anti-human school of thought such as cosmism which advocates complete dissolution of the corporeal entity of human beings and subsequent transformation into technogenetic entities Critics like Higo De Garis believe in infinite alteration of the human body through genetic and technological augmentations, such views significantly echo transhumanist desire of anthropocentricism, continued through assimilation of the techo-genetic other.

Donna J, Haraway writes in her essay titled "Value added Dogs and Lively Capital" Marx understood "relational sensuousness, and he thought deeply about the metabolism between 
human beings and the rest of the world enacted in living labour" (Rajan, 2006, p. 93). But Marx falls in the trap of the same human essentialist historiography he sought to challenge as for Marx there is only one teleological point "the man" for Haraway notes that there are "no companion species"," reciprocal inductions", or "multispecies epigenetics" in Marx's narrative of emancipation. For Haraway the notion of companion species is of prime importance as it dilutes the hierarchical patterns of anthropocentric structures of human oriented mapping of ecology. This includes a complete dismantling of the nature culture boundaries as well as the rigid walls of species for multispeciesism and trans- species relationships i.e., "becoming with each other in nature cultures is the name of the game of life on earth; the partners do not precede their dynamic knottings. Critters, human and not, make each other up in flesh and sign, literally and figuratively" (Rajan, 2006, p. 94). Haraway elaborates on her notion of the companion species and critter further in her celebrated book Staying with the Trouble: Making kin in the Chuthulucene, where she notes that companion species can actively transform the earth into "Terrapolis" a world made up of "compost", and inoculated against human exceptionalism but rich in humus, ripe for multispecies storytelling" (Haraway, 2016, p. 11). Terrapolis resists the euro-centred globalization and capitalocene as the Homo of the terrapolis is not Marx's Homo Economicus but rather "the human that is transmogrified in etymological Indo-European sleight of tongue into guman, that worker of and in the soil" (Haraway, 2016, p. 11).

Companionship is functional on the similar understanding of matter (both biotic and abiotic) what Karen Barrad calls 'intra-actions', or the mutual constitution of entangled agencies. Companionship produces sympoesis which challenges any notion of auto-ontological arrival such as the coming of the human beings through a teleological evolutionary track. For as Haraway explains "sympoesis enlarges and displaces autopoesis and all other self-forming and selfsustaining system fantasies. Sympoesis is a carrier bag for ongoingness, a yoke for becoming with" (Haraway, 2016, p. 125). This becoming with is the essential modality of animality as Giles Deleuze and Felix Guattari postulate in A Thousand Plateaus "becoming animal" "always involves a pack, a band, a population, a peopling, in short, a multiplicity" (Deleuze, 1987, p. 239). Deleuze and Guatari categorically place the "animal" in three distinctive groups the first being the close animal associates of humans - the pets whom they term as the Oedipal animal, they invite continuous "narcissistic contemplation" (Deleuze, 1987, p. 240), and they are "the only kind of animal psychoanalysis understands" (Deleuze, 1987, p. 240). The second category the State animal is treated in great divine myth and "Finally, there are more demonic animals, pack or affect animals that form a multiplicity, a becoming, a population (Deleuze, 1987, p.240-41). The "demonic animal" as Deleuze and Guattari elucidate, is an assemblage of multiple series of affects - ungraphed.The animal correctly, if deduced, constitutes a privileged figure for the problem of difference and subjectivity generally, because it constantly announces how the subject is always already multiple:

The animal is inseparable from a series exhibiting the double aspect of progressionregression, in which each term plays the role of a possible transformer of the libido (metamorphosis). A whole approach to the dream follows from this; given a troubling image, it becomes a question of integrating it into its archetypal series. That series may include feminine, masculine, or infantile sequences, as well as animal, vegetable, even elementary or molecular sequences. (Deleuze, 1987, p. 235) 
Similarly, Haraway frames a complementary ethics of being "multiple" in her Simian, Cyborg and Women: The Reinvention of Nature, which she terms as "Splitting". Splitting is the advantageous icon of feminist epistemologies of scientific understanding according to her for it counters the hegemonic masculine assurance of "being" through division and plurality. 'Splitting' initiates "heterogeneous multiplicities that are simultaneously necessary and incapable of being squashed into isomorphic slots or cumulative lists" (Haraway, 2013, p. 193). In her celebrated essay "Cyborg Manifesto" (1984), Haraway had already established that the synthesis of human and machine also has important repercussions for other abstract distinctions such as that between human and animal as subjectivity is not a homogenous uni-dimensional extension but a continuous fracture on the ontological border breeding multiplicity. According to Haraway "The topography of subjectivity is multidimensional; so, therefore, is vision. The knowing self is partial in all its guises, never finished, whole, simply there and original; it is always constructed and stitched together imperfectly, and therefore able to join with another, to see together without claiming to be another" (Haraway, 2013,p. 193). It must be noted here that Deleuze and Guattari's orientation of animality in the direction of multiplicity is raised in a different register by Donna Haraway. In the ethical status of nonhuman others, animal nonhuman others have priority in Deleuze's formulations, but not according to Haraway, whose cyborg would take its place alongside the chimpanzees of animal rights philosophy and the wolf packs of $A$ Thousand Plateaus.

Non recognition of this multiplicity of "animality" in its numeric as well as its ontological reverberations "is not simply a sin against rigorous thinking, vigilance, lucidity or empirical authority," according to Derrida "it is also a crime. Not a crime against animality precisely, but a crime of the first order against the animals, against animals" (Derrida, 2008, p. 73). The infinite multiplicity of the other can only be repressed through violence and wilful violence as Derrida points. Violence, which is initiated through the language which man credits and consolidates as the prime faculty of departure from the other, the non-human animal, is tuned towards the animal to put the category under ellipses. The word animal emerges as catachresis as the collation of numerous individuals, several animality under which the human coerces the other deliberately, to serve as its trace, to perform the function of the binary opposite. Derrida notes the unfolding of such a catachresis and exclaims:

Confined within this catch-all concept, within this vast encampment of the animal, in this general singular, within the strict enclosure of this definite article ("the Animal" and not "animals") ... are all the living things that man does not recognize as his fellows, his neighbours or his brothers . (Derrida, 2008, p. 51)

The taxonomical imperative, through which the anthropocentric thought appropriates the animal, in an all engulfing one, troubles the seemingly stable category of the human too. Giargio Agamben points out the problem of taxonomy which haunts the Homo Sapiens using the instance of Carl Linnaeus the father of modern taxonomy. The entanglement of the animal in philosophical conception of man can be understood, as Agamben points out, in the fact that Linnaeus places man among the primates as also in the "irony with which he does not record-as he does with the other species-any specific identifying characteristic next to the generic name Homo, only the old philosophical adage: noscete ipsum \{know yourself\}" (Agamben, p. 25). Even in the tenth edition of Linnaeus's Systema Naturae, when the complete denomination of human beings 
becomes Homo sapiens, "the new epithet does not represent a description, but that it is only a simplification of that adage, which, moreover, maintains its position next to the term Homo" (Agamben, 2004, p. 25). The containment of man in a secured ideological bubble requires the trace of the animal in order to define itself.

It must be pointed out that the Posthuman vision initiates a post-Cartesian approach which advances through recognitions, instead of assimilations. Such unconditional hospitality requires a rethinking of the ethics and the "ethical" brings in human essentialism in the posthuman discourse, as ethics is understood as essentially a human faculty. The question arises regarding the return of the human in guise of the ethical, but the posthuman ethics initiates a non-masculinist rationality treating life as a non valorised minimal condition full of ruptures, fractures and continuous becoming. Posthuman ethics produces new, speculative ways of recognising relations between lives. Ethics is essentially an exercise in adaptive and creative interaction, and continuously avoids claims to moral structures or meta-narratives. Ingrained in the posthuman ethics is the eminence of bodies as the locale of lives, as points in networks, inseparable from philosophy, thought, experiments in being and speculations of the future- a future which is definitely postanthropocentric. As Joanna Zylinska opines "post-anthropocentric ethics of obligations becomes a way of taking responsibility, by the human, for various sorts of thickenings of the universe, across different scales, and of responding to the tangled mesh of everyday connections and relations" (Zylinska, 2014, p. 17). The present research paper recognizes that philosophy of life cannot be initiated from zero degree, even if it is situated beyond the ethico- juridical imperative as "bare life", for no matter how hospitable life becomes to its immediate milieu, it infuses its ardour into the environment.

The inter species relationship is an inter-active becoming which cannot be and should not be dressed using any linear ethical pattern. The "other"-the animal- is not the straightforward antithesis, to human, nor can the animal be rendered all transparent. As Cary Wolfe points out in the context of the subjective formation of the human cannot be grasped and saved unless that other part of itself, the share of things, is restored to it. The position of the animal as Wolfe opines is enmeshed within the larger framework of posthumanist theory, within which the ethical and theoretical problems of nonhuman subjectivities are triggered incessantly. For Regan this position is "the subject of a life"" (Wolfe, 2003, p.190). "Subject of a life" are beings who possess "beliefs and desires; perception, memory, and a sense of the future, including their own future; an emotional life together with feelings of pleasure and pain; preference- and welfare-interests; the ability to initiate action in pursuit of their desires and goals; a psychophysical identity over time; and an individual welfare" (Wolfe, 2003, p. 243). Any such distinction and extension of moral and ethical treatment grounded on the criteria of perceptive and participatory behaviour is not only exclusionary but is also discriminatory and continues the humanist utilitarian perception of nature/animal. Wolfe notes, Derrida "reminds us [that] .... there can be no "science" of ethics, no "calculation" of the subject whose ethical conduct is determined in a linear way by scientific discoveries about animals" (Wolfe, 2003, p. 190). The key is not to search for ethical difference in the "other"/animal, but instead to be open, to be unconditionally hospitable to the possibilities in the other beings that are most un like the self/ man. "A principle of ethics or more radically of justice", according to Derrida, "is perhaps the obligation that engages my responsibility with respect to the most dissimilar ... the entirely other, precisely, the monstrously other, the 
unrecognizable other. The 'unrecognizable' . . . is the beginning of ethics, of the Law" (Derrida, 2008 , p.54). He doesn't discriminate the animal on the basis of their capacity to respond, like Jacques Lacan for whom an animal is not "a subject of the signifier" because it lacks "the locus of the Other." Thus, an animal can "pretend" but not "deceive"; it cannot, for example, "cover up its tracks" (Steiner, 2013, p.89). According to Lacanian psychoanalysis the animal is devoid of an inner world or Innenwelt for the animal is perpetually stationed in the imaginary realm and lacks access to the symbolic order. The animal for him, lacks desire and the unconscious, that animals can be gregarious but not social-Lacan seems to further the humanist prejudice that human beings can "respond" but animals can merely "react."

There are two drastically divergent ways in which the poststructuralist/posthuman philosophy treats the problem of speciesism, the wide abyss between the subjects, that names itself the man and names the other as animal, remains a matter of excavation. For Agamben the wholesale abandonment of the distinction between the man and animal can lead to a formulation of nonanthropocentric ontology, a movement then will be made possible towards a "relational ontology" through which the violence towards the animal can be addressed and mitigated. He writes in The Open Man and Animal that "Homo sapiens, then, is neither a clearly defined species nor a substance; it is, rather, a machine or device for producing the recognition of the human" (Agmaben,2004, p. 26). This machine, precisely the "anthropological machine", as Agamben terms it, is an ironic one:

because the human is already presupposed every time, the machine actually produces a kind of state of exception, a zone of indeterminacy in which the outside is nothing but the exclusion of an inside and the inside is in turn only the inclusion of an outside.( Agamben, 2004, p. 37)

For Haraway dilution of the species boundary, which Agamben advocates, is emancipatory for the "tentacular" other as it provides possible way to subvert the genealogy and ancestry of the hegemonic system of ordering the zoo-ontology through making "kin". The way forward through which anthropocene and capitalocene can be challenged is through the initiation of "multispecies ecojustice" (Haraway,2016, p. 101) She notes that "No species, not even our own arrogant one pretending to be good individuals in so-called modern Western scripts, acts alone; assemblages of organic species and of abiotic actors make history, the evolutionary kind and the other kinds too" (Haraway, 2016, p. 100). The assemblages of the organic beings and the abiotic components are entangled in a tentacular manner which she calls "Chuthulucene" which "does not close in on itself; it does not round off; its contact zones are ubiquitous and continuously spin out loopy tendrils" (Haraway, 2016, p.33). Deriving from H. P. Lovecraft's swampy monster "Chuthulus" Haraway instils in the term a multiagency, a tentacular precision through which it "entangles myriad temporalities and spatialities and myriad intra-active entities - in- assemblages -including the more- than- human, other- than- human, inhuman, and human- ashumus ( Haraway, 2016, p. 101). Haraway's politics of knotting which she allies with Bruno Latour's Actor Network Theory seeks to congeal all biotic matterings under the colloquial term critter, she writes in When Species Meet "the infolding of others to one another is what makes up the knots we call "beings" or, perhaps better, following Bruno Latour, things. Things are material, specific, non-self-identical, and semiotically active. In the realm of the living, critter is another name for thing" (Haraway, 2006, p. 250). 
Derrida, however, is distrustful of such prescriptive discourses which make the species boundary inconsequential as firstly, morality and judgement cannot be administered in such objective manner for then they would become assessable empirical quantities of science. Secondly, as Cary Wolfe points out "it reduces ethics to the very antithesis of ethics by reducing the aporia of judgment in which the possibility of justice resides to the mechanical unfolding of a positivist calculation" (Wolfe, 2010, p. 69). Derrida is well aware of the aporiatic nature of the justice and morality which governs the inter species distinction and doesn't claim to be complete cognitive control of the complex nature of such networks of relations and thus he writes in recognition of the abyss between man and animal in following words:

I have thus never believed in some homogeneous continuity between what calls itself man and what he calls the animal. I am not about to begin to do so now... To suppose such a stupid memory lapse or to take to task such a naive misapprehension of this abyssal rupture would mean, more seriously still, venturing to say almost anything at all for the cause...

(Derrida, 2008, p. 45-46)

Matthew Calarco find Derrida's refusal to abandon the distinction between man and animal "to be one of the most dogmatic and puzzling moments in all of his writings." (Calarco, 2008, p. 145) Wolfe has grasped the rationale behind Derrida's denial to discard the human-animal division by pointing out that for Derrida, the abyss that separates humans from animals is same that also differentiates between different sorts of living beings. In other words, "the abyss separating human beings from animals has no special privilege but is simply another instance of the irreducible and mysterious ways in which dogs differ from cats; one cat differs from another cat; one human being differs from another human being; and even the way in which, in virtue of the play of the trace, one human being or dog or cat differs from itself" (Steiner, 2013, p. 115).

The issue of interspecies companionship and its ethical prerogative is also a contentious one as ethics, friendship, companionship all are human created episteme, which at some level or the other facilitate human autocracy. Haraway interrogates thus, 'Whom and what do I touch when I touch my dog?' (Haraway, 2007, p. 3). She expounds the plethora of other- than -humans from a posthuman perspective - the cyborgs, apes, monkeys, oncomice and dogs as both imagined figural entities as well as ordinary lived organisms (Haraway, 2007). However, in spite of her desire to overthrow human tyranny Haraway maintains deeply troubling anthropocentric possessions quite unconsciously. Her use of possessive pronoun 'My' and the word 'dog' in tandem are antithetical to a true "posthuman ethics of nonhumanity". Her dog is, by being her companion, the Oedipal dog. As Patricia Mac Cormac points out "In spite of her second question, which is 'how is becoming with a practice of becoming worldly' (Haraway, 2007, p.3) Haraway has missed the territory which diverges human Oedipal families to which the dog 'belongs' from the abstract animal machines of becomings" (MacCormac, 2016, p.63). As Deleuze and Guattari write:

there is a becoming-animal not content to proceed by resemblance and for which resemblance, on the contrary, would represent an obstacle or stoppage; the proliferation of rats, the pack, brings a becoming-molecular that undermines the great molar powers of family... there is a circulation of impersonal affects, an alternate current that disrupts signifying projects as well as subjective feelings, and constitutes a nonhuman sexuality; and 
there is an irresistible deterritorialization that forestalls attempts at professional, conjugal, or Oedipal reterritorialization. ? (Deleuze, 1987, p. 233).

In being treated as Oedipal the multiplicity, the "being pack" that animal contains is rendered merely 'virtual'. The reterritorialization of the animal as a companion being as Oedipal animal produces filiation and involutions rather than hereditary production and sexual production. The wild or the demonic "band" of animal, in contrast, presupposes contagion, a rhizomatic proliferation as Deleuze and Guattari write "humans and animal, proliferate by contagion, epidemics, battle fields and catastrophes" (Deleuze ,1987, p. 266). It is through contagion and multiplicities, write Deleuze and Guatari in the "1730 Plateau" that assemblages are produced "it is there that human beings effect their becoming-animal" (Deleuze, 1987, p. 267). For Deleuze "The pack is simultaneously animal reality and the reality of the becoming-animal of the human being" (Deleuze, 1987, p. 267). Patricia MacCormack provides a comparison between the two conceptions of the animal the Oedipal and the demonic, for she notes that "Haraway seeks to naturalize the unnatural participation of dog and human, conveniently looking for sympathetic reconfigurations of domestication and .... companionship is how she elegantly ablates the fact of dogs being enslaved through domestication" (MacCormack, 2016, p. 64).In contrast "Deleuze and Guattari show a belief in unnatural participations being here and now, the not-right as in not logical or based on commensurability within taxonomies... by seeing the unnatural as the only ethical direction, shows both our responsibility and urgency in refusing the politics of comfort" this (MacCormack, 2016, p. 64) make bare the basis of human-nonhuman mired in disgust and subjugation.

The posthuman ethics does fold within itself various human essentialist attributes such as companionship, friendship, kindness, love and responsibility and Joana Zyliniska proposes that posthuman ethics "spring from the recognition of the strategic role of the concept of the human in any kind of ethical project worth its salt" (Zyliniska, 2014, p. 61). But any unfolding of the posthuman ethics while intracting with the "animal" must be conscious of the human presence in its conceptual building and such essentialism must be guarded against. As Michel Serres demands the posthuman ethics must portray grace and "Grace is nothing, it is nothing but stepping aside. Not to touch the ground with one's force, not to leave any trace of one's weight, to leave no mark, to leave nothing, to yield, to step aside ... to dance is only to make room, to think is only to step aside and make room, give up one's place. (Serres, 1995, p.7)

\section{Reference:}

Agamben, Giorgio. (2004). The Open: Man and Animal. Stanford university press.

Calarco, Matthew. (2008). Zoographies: The Question of the Animal from Heidegger to Derrida. Columbia University Press.

Coetzee, John Maxwell. (2016). The Lives of Animals. Princeton University Press.

Deleuze, Giles and F. Guattari. (1987). "A Thousand Plateaus: Capitalism and Schizophrenia." Trans. by Massumi, B., University of Minnesota, Minneapolis.

Derrida, Jacques. (2008). The Animal that therefore I am. Fordham Univ Press. 
Haraway, Donna Jeanne. Primate Visions: Gender, Race, and Nature in the world of Modern Science. (1989). Psychology Press.

-- (2003). The Companion Species Manifesto: Dogs, People, and Significant Otherness. Vol. 1. Chicago: Prickly Paradigm Press.

-- (2013). Simians, Cyborgs, and Women: The Reinvention of Nature. Routledge.

-- (2016). Staying with the Trouble: Making Kin in the Chthulucene. Duke University Press.

Latour, Bruno. (2004). Politics of Nature. Harvard University Press.

-- (2012). We have never been Modern. Harvard University Press.

-- (2013). An Inquiry into Modes of Existence. Harvard University Press.

MacCormack, Patricia. (1995). Posthuman Ethics: Embodiment and Cultural Theory. (2016). Routledge.

Serres, Michel. "Genesis."

--(2013). The Parasite. Vol. 1. U of Minnesota Press.

Wolfe, Cary. (2010). What is Posthumanism? Vol. 8. U of Minnesota Press.

Wolfe, Cary. (2003). Animal Rites: American culture, the discourse of species, and Posthumanist theory. University of Chicago Press.

Zylinska, Joanna. (2014). Minimal Ethics for the Anthropocene. Open Humanities Press. 